\title{
The use of selected research methods to describe the pore space of dolomite from copper ore mine, Poland
}

\author{
Anna Pajdak ${ }^{1} \cdot$ Katarzyna Godyń $^{1} \cdot$ Mateusz Kudasik ${ }^{1} \cdot$ Tomasz Murzyn $^{1}$
}

Received: 10 January 2017/ Accepted: 24 May 2017/Published online: 31 May 2017

(C) The Author(s) 2017. This article is an open access publication

\begin{abstract}
Basic knowledge of the characteristics of copper-bearing rock such as dolomite is essential to locate those areas of the deposit which have different structural and textural properties. Those regions can be important in terms of the assessment of the possibilities of gas accumulating in them as well as in terms of gasogeodynamic hazard. To better understand those threats, it is necessary to locate, monitor and analyse those areas in detail. This article characterises the structural and textural parameters of dolomite from the Polkowice-Sieroszowice copper mine in Poland. The study involved five samples from various areas of the mine. A number of research methods were selected. Reflected and transmitted light microscopy (MS), computer microtomography (Micro-CT), gas adsorption porosimetry (LPNA), mercury porosimetry (MIP), helium and quasi-fluid pycnometry (Pycno. He, DryFlo). Each of the methods examined a different scope of the pore size, which enabled to achieve a full view of the porous nature of those rocks. We determined their porosity (open, closed, total), surface area as well as mean size and volume of the pores. Also, we studied the character and the pore size distribution from a few $\mathrm{nm}$ to a few $\mathrm{mm}$. Comprehensive
\end{abstract}

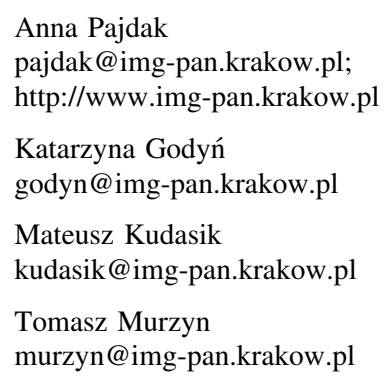

Mateusz Kudasik

kudasik@img-pan.krakow.pl

Tomasz Murzyn

murzyn@img-pan.krakow.pl

1 The Strata Mechanics Research Institute, Polish Academy of Sciences, Reymonta 27, 30-059 Kraków, Poland dolomite properties analyses showed that these rocks are characterised by high structural variability. They have mesopores and macropores but few micropores. The analyses presented in this paper are determined by a large petrographic diversity of the deposits containing dolomite. This article is an example of a comprehensive approach to the rock analysis in copper ore mines.

Keywords Dolomite $\cdot$ Copper ore mine $\cdot$ Structural properties · Porosity

\section{Introduction}

Mining is a branch of industry involving a lot of risk, which is connected with the presence of numerous natural threats. As the depth of mining increases, so does the probability of the occurrence of hazards (Hargraves 1983; Díaz Aguado and González Nicieza 2007; Szlązak 2013). Some of the most serious problems in mining are gas hazards, which are directly connected with the following factors: (1) gas and rock outbursts risk, (2) the presence of explosive gases and (3) the presence of toxic gases in the deposits (Skoczylas 2014; Wierzbicki and Skoczylas 2014).

The gas and rock outburst hazard is defined as a possible occurrence of gasogeodynamic phenomena (Lama and Bodziony 1996). As a result, the rock material is crushed and the mixture of gas and rock is driven to the excavation area (Beamish and Crosdale 1998; Cao et al. 2001). The process is initiated mainly by the energy of the gas released from the rock mass.

The outburst hazard results directly from the presence of gas in the rock. There is a real risk of explosions of mixtures of methane $\left(\mathrm{CH}_{4}\right)$ in mine workings, which is present in most currently exploited coal deposits and is 
created naturally in carbonisation process (Wierzbicki and Młynarczuk 2006; Manecki and Muszyński 2008). In the years 2009-2014, the Polish mining industry experienced 18 incidents of methane explosion or ignition killing 25 and injuring 71 miners (State Mining Authority 2015).

The risk of toxic gas poisoning is due to the presence of hydrogen sulphide $\left(\mathrm{H}_{2} \mathrm{~S}\right)$, which particularly accompanies the production of natural gas and crude oil. However, its presence was also recorded in coal mines in South Africa, Russia, China, France and Australia (Harvey et al. 1998; Swart et al. 2000; Mingju et al. 2012). Until 2009 in Polish copper mines, the hydrogen sulphide hazard was marginal as compared to other natural threats (Dziedzic et al. 2007). In September 2010, the presence of $\mathrm{H}_{2} \mathrm{~S}$ was recorded for the first time in a Polish copper mine Polkowice-Sieroszowice (Kijewski et al. 2012). Trace amounts were detected locally in mine workings in anhydrite layers by the characteristic odour. A year later in October 2011, in the first accident of this kind, one miner was severely poisoned with hydrogen sulphide (State Mining Authority 2012).

In recent years, all the aforementioned hazards connected with the presence of gas in rock have also occurred in Polish copper mining industry. The gas closed in pores of copper-bearing rock is more and more often noted in Polish copper mines. In September 2009, in a Polish copper mine Rudna, the presence of gas in deposits resulted in a gas and dolomite outburst in Zechstein dolomite at a depth of $1200 \mathrm{~m}$ (Wierzbicki and Młynarczuk 2013). It was the first such accident worldwide. As a result, a 70-m-long section of the excavation area was filled with rock material. It is thought that the outburst may have been caused by the excavation front approaching the deposits of natural gas. They were being exploited at a depth of $1500 \mathrm{~m}$ and located over ten kilometres away from the copper mine. Samples of postoutburst mass extracted at the site were analysed at the Strata Mechanics Research Institute of the Polish Academy of Sciences. The analyses showed that high-porosity epigenetic dolomites were responsible for that phenomenon. They had different structural and textural properties, including among others, 20\% higher porosity on average. Half of the total pore structure was closed pores containing residual gases, mainly nitrogen $\left(\mathrm{N}_{2}\right)$, trace amounts of carbon dioxide $\left(\mathrm{CO}_{2}\right)$ and hydrocarbons. Those gases may have filled the closed pores under considerable pressure for a long period of time. The laboratorially analysed pores of the post-outburst mass contained gas under pressure of at least $4 \mathrm{MPa}$, which may have been at such a level for many months. The studies of various parts of the mine working showed that the dolomite had such different structural and textural properties in limited areas.
Polish copper deposits are among the largest in the world. Active mining zones cover an area of about $600 \mathrm{~km}^{2}$ (Alderton et al. 2016). The annual copper production amounts to nearly 570 thousand tones and silver production to 1200 tones. Taking into account, the concession areas of KGHM Polish Copper, it ranks Poland the eighth in the world in terms of copper resources and the second in terms of silver resources (U.S. Geological Survey 2015). The appearance of a potential gas hazard in copper mines in Poland in recent years created a need for research into this phenomenon (Butra and Orzepowski 2001). The only available research data of the post-outburst mass coming from Rudna copper mine, where the outburst occurred, indicate that the most gasogeodynamic phenomena prone areas are those of different structural properties (Wierzbicki and Młynarczuk 2013). Thus the identification of gasogeodynamic hazard in copper mines should be made mainly through locating such areas in the deposit.

In December 2015, an unnatural phenomenon of dolomite spattering from the sidewall after blasting was observed in Polkowice-Sieroszowice copper mine in Poland. It might indicate that some of the rocks there had different structural and textural properties. That fact inspired the authors to analyse in detail the samples of the dolomite rock from that region. This paper characterises the structure of dolomite using a number of research methods: optical, microtomographic, porosimetric and densitometric.

\section{Geological setting}

The copper-bearing formations of Lower Silesia, exploited by KGHM Polska Miedź S.A, cover the area of the Legnica-Głogów Copper Belt (Pytel 2003) (Fig. 1). Those formations include the mining area of PolkowiceSieroszowice mine. It is of sedimentary, strata-bound type and comprises Zechstein cyclothem PZ1 (cyclothem Werra, Z1) and the Rotliegend and the Weissliegend sandstones (Konopacka and Zagożdżon 2014; Wodzicki and Piestrzyński 1994). The deposit is located in the monocline at the depth from a few hundred metres (SW) to $1500 \mathrm{~m}(\mathrm{NW})$. Formation of copper minerals in that region occurs in three types of rock: sandstone, shale and dolomite (Fig. 2).

Since the outburst in Rudna copper mine, the researcher's attention has been focused mainly on dolomite rocks. They vary in terms of their origin, which determines their structural and textural properties. These rocks are formed as a result of metasomatism of limestone (Manecki and Muszyński 2008), which involves partial replacement of calcium carbonate $\left(\mathrm{CaCO}_{3}\right)$ with 


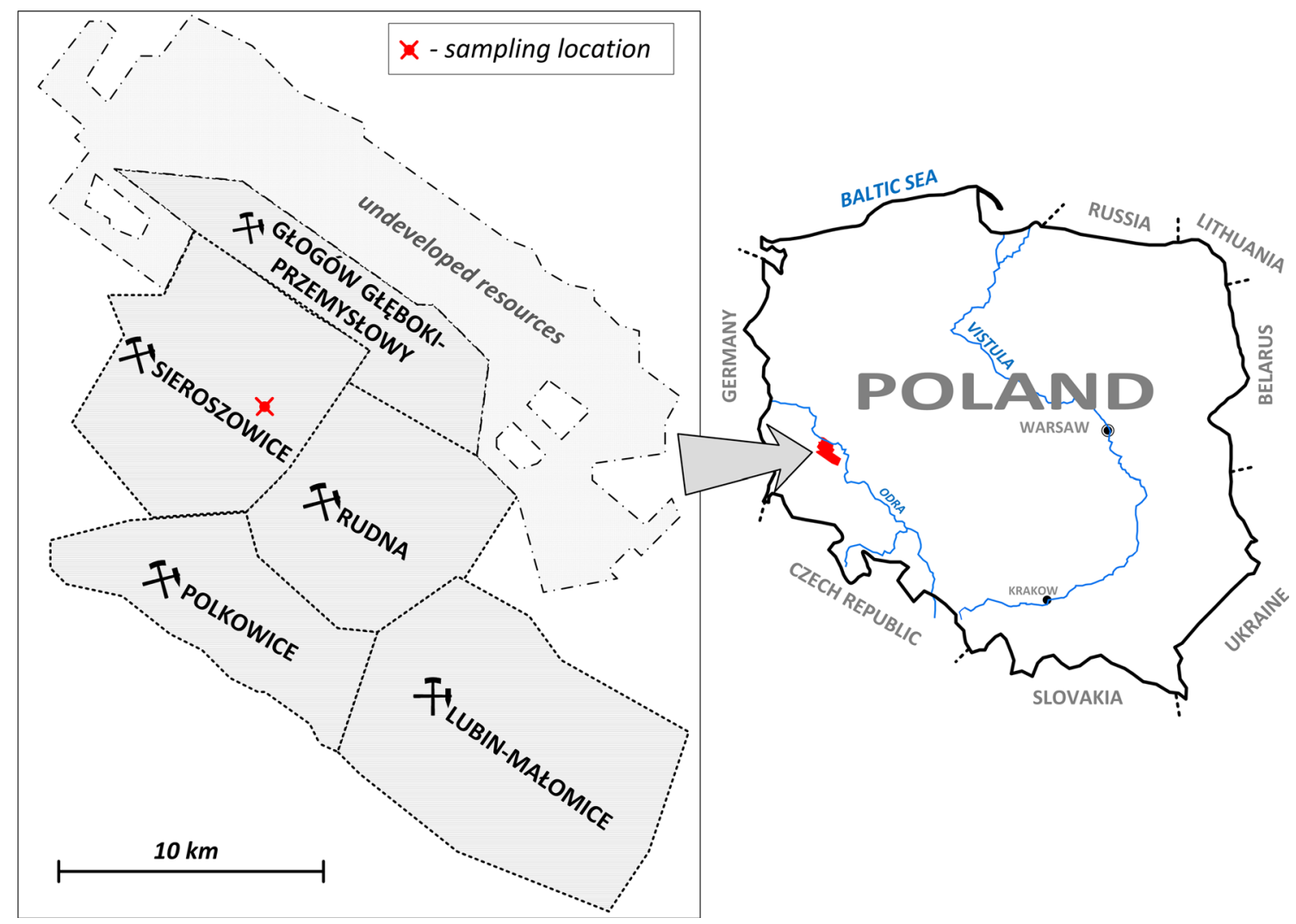

Fig. 1 Distribution of copper ore deposits in the area of the Legnica-Głogów Copper Belt (based on KGHM)

magnesium carbonate $\left(\mathrm{MgCO}_{3}\right)$ from sea water (epigenetic dolomite), and dolomitisation of lime mud precipitated out of water (diagenetic dolomite). Transformation of lime mud into dolomite is accompanied by a decrease in volume by up to $12 \%$ thus secondary dolomite is cavernous and porous (Książkiewicz 1979; Bolewski and Parachoniak 1982; Manecki and Muszyński 2008). The increased porosity in secondary-epigenetic dolomites is the main reason for the detailed analyses of those rocks, especially in the context of the issues connected with outbursts. Moreover, Zechstein Main Dolomite formations located to the north, on the area of the Polish Lowland, are host and reservoir rocks for hydrocarbons deposits (Czekański et al. 2010). Based on the studies of the rocks from Polish mine workings (Pajdak and Kudasik 2016; Godyń 2016), and by the IUPAC standards (Rouquérol et al. 1994), typical dolomites have mainly macropores with diameter size $D>0.050 \mu \mathrm{m}$ and mesopores $(0.002 \mu \mathrm{m} \leq D \leq 0.050 \mu \mathrm{m})(\mathrm{Li}$ et al. 2003).

The research material comprised five samples of carbonate rock (dolomites) from Polkowice-Sieroszowice copper mine (D1-D5). The samples were extracted from different areas of the mine. After initial comminution, they were divided into portions and designated for particular analyses.

\section{Analytical techniques}

Axioplan polarisation microscope by Zeiss and computeroperated mechanical table XYZ were used for the petrographic analysis. The image from the microscope was displayed on the monitor due to the application of the Nicon CCD DSFil Camera. The samples were analysed in transmitted and reflected light at $50 \times, 100 \times, 200 \times$ magnifications. To assess the total and open porosity of the samples quantitative point counting analysis was used within the limits of the microscope, i.e. for pores with the diameter size above $3 \mu \mathrm{m}$.

In order to specify the open porosity, the rock samples were saturated with contrasting coloured resin, which filled the pores visible to the microscope. After the thin section was made, the pores were visible as light blue spots. In order to determine the total porosity in the samples polished sections were made and analysed in reflected light. After the rock was cut the open pores became visible and the closed pores opened. Knowing the area covered by pores, it was possible to specify the total porous space of the dolomite samples. The closed porosity was determined from the difference between the total and open porosity.

The quantitative analysis was performed based on the Cavalieri-Hacquet principle (Ryś 1995), whereby the 


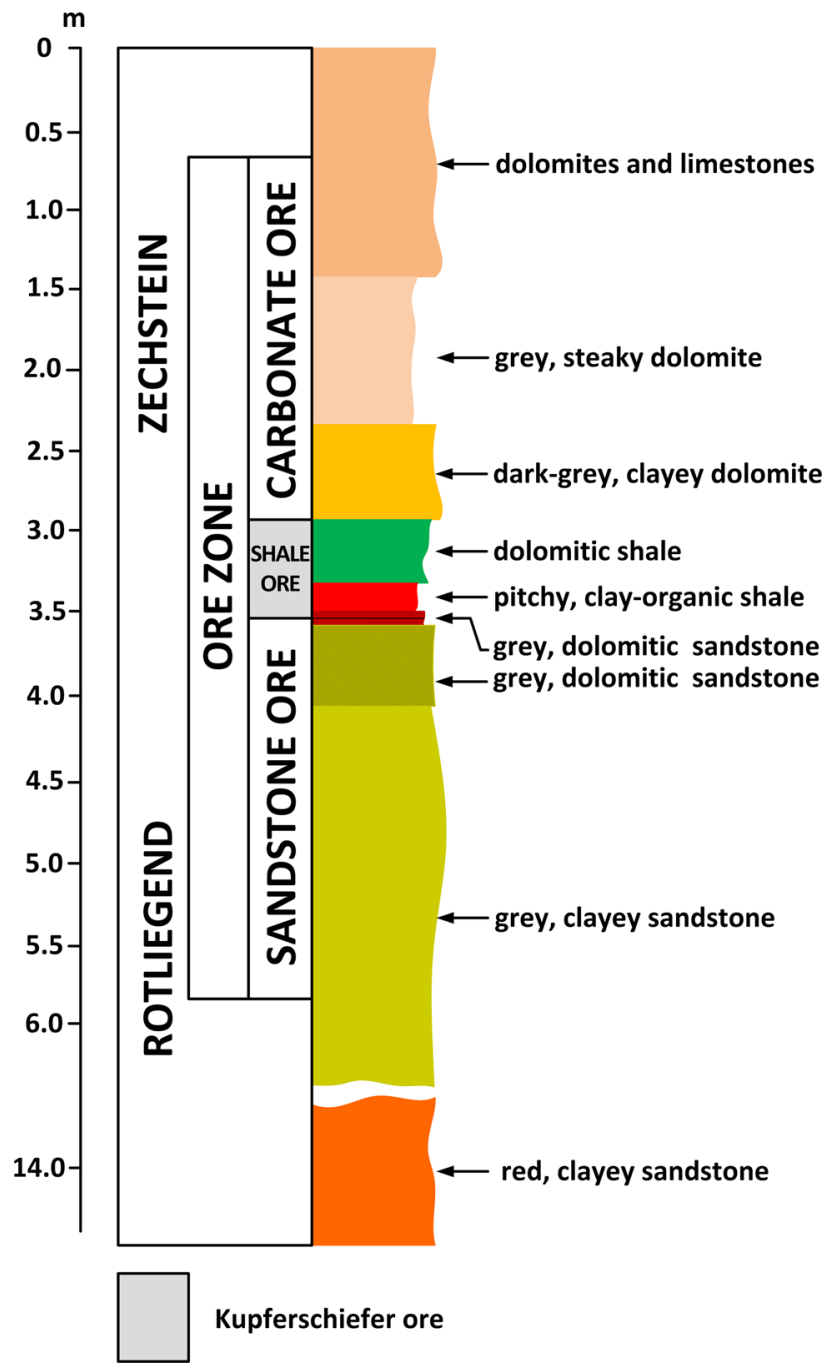

Fig. 2 Schematic profile copper deposits exploited by KGHM in the Legnica-Głogów Copper Belt (KGHM)

percentage of a given phase in the rock volume is the same on the cutting plane and on its flat section. The required number of measurement points for each cut and polished specimen was determined from the following equation:

$z=\frac{u_{\alpha}^{2} \times\left(1-V_{\mathrm{V}}\right)}{\delta_{\mathrm{r}}^{2} \times V_{\mathrm{V}}}$,

where $z(-)$ is number of measurement points, $u_{\alpha}(-)$ is coefficient read from the normal distribution tables, $\delta_{\mathrm{r}}(-)$ is relative error of measurement, $V_{\mathrm{V}}(-)$ is number of points of the least numerous component of the analysed phase (rock pores).

Microtomographic analyses were carried out using Benchtop CT160Xi (X-tech Nikon). The research method involved emitting an X-ray beam. After passing the sample, it become attenuated due to dispersion and absorption. The attenuation of the X-ray was determined according to the Beer-Lambert law: $\mathrm{d} I=-\mu \times I \times \mathrm{d} x$,

where $\mathrm{d} I\left(\mathrm{~W} / \mathrm{m}^{2}\right)$ is change of the radiation intensity, $\mu(1 / \mathrm{m})$ is total absorption coefficient, $I\left(\mathrm{~W} / \mathrm{m}^{2}\right)$ is intensity of the beam passing through the absorbent, $x(\mathrm{~m})$ is thickness of the absorbent.

The changes of X-ray intensity of the samples were registered for the successive angle positions of the samples in the range of $0^{\circ}-360^{\circ}$. Two dolomite samples, for which the stereological analyses showed the highest and the lowest values of total porosity, were designated for the tests. The images were taken at the lamp voltage of $75 \mathrm{kV}$ and light intensity of $110 \mu \mathrm{A}$. The scanning time of each $9 \mathrm{~mm}$ diameter sample was $2.5 \mathrm{~h}$.

Analyses with Mercury Intrusion Porosimetry (MIP) method were carried out on lump samples using two mercury porosimetres Pascal (Thermo Scientific) including low-pressure module Pascal 140 and high-pressure module Pascal 440.

The studies involved a measurement of mercury $(\mathrm{Hg})$ volume, which penetrated the open pores as the pressure rose, under strictly controlled conditions. Before the measurement, the samples were crushed to particles of irregular shapes with the diameter of 5-10 $\mathrm{mm}$ and outgassed. The measurement chamber in which the sample was placed was filled with mercury and subjected to pressure. As the pressure rose, the mercury intruded into smaller and smaller open pores until the pores with the diameter comparable to a mercury particle were filled. The mercury intrusion occurred in the pressure range of 10-5-10$1 \mathrm{MPa}$-Pascal 140 and 0.1-150 MPa-Pascal 140. Bulk and skeletal volume were specified, and the percentage of open porosity was calculated from the following formula:

$\emptyset=\frac{V_{\mathrm{sk}}-V_{\mathrm{b}}}{V_{\mathrm{sk}}} \times 100 \%$,

where $\emptyset(\%)$ is open porosity, $V_{\text {sk }}\left(\mathrm{cm}^{3}\right)$ is the skeletal volume, $V_{\mathrm{b}}\left(\mathrm{cm}^{3}\right)$ is the bulk volume.

According to the Washburn's theory (Washburn 1921), it was assumed that the size of the pore diameter, providing they are of cylindrical shape, is described by Eq. (4), and the surface area, calculated per unit of mass of the analysed material is described by Eq. (6):

$D=-\frac{4 \times \gamma \times \cos \theta}{\Delta p}$,

according to the assumption:

$\Delta p=p_{1}-p_{0}$,

$S=-\frac{1}{\gamma \times \cos \theta} \int p \times \mathrm{d} V$,

where $D(\mu \mathrm{m})$ is pore diameter, $\gamma(\mathrm{N} / \mathrm{m})$ is surface tension, $\theta\left(^{\circ}\right)$ is wetting angle, $\Delta p(\mathrm{~Pa})$ is difference between the 
mercury pressure and gas pressure in the pores, $p_{1}(\mathrm{~Pa})$ is hydrostatic pressure of mercury, $p_{0}(\mathrm{~Pa})$ is gas pressure in the pores of the sample, $S\left(\mathrm{~m}^{2} / \mathrm{g}\right)$ is surface area, $V\left(\mathrm{~cm}^{3} / \mathrm{g}\right)$ is pore volume.

During the measurement, simplifications were made consisting in omitting the pressure and assuming a constant surface tension of mercury equal to $0.48 \mathrm{~N} / \mathrm{m}$ and a constant wetting angle of mercury-141.3.

The MIP measurements allowed to analyse the mesopores and macropores of the dolomite in the 0.05-100 $\mu \mathrm{m}$ range. For those pores, the differentiable function $f$ of the pore size distribution was determined according the following formula:

$f=-\frac{\mathrm{d}(V)}{\mathrm{d}(\log D)}$.

The low-pressure nitrogen adsorption (LPNA) analyses were carried out using ASAP 2020 analyser. Before the measurement, the rock samples were comminuted in an original impact mill (Kudasik et al. 2014). For the purpose of the research, the samples were sieved to the fraction of $0.34-0.63 \mathrm{~mm}$. Subsequently, they were degassed in the temperature of $105{ }^{\circ} \mathrm{C}$ for $2 \mathrm{~h}$ and analysed in the absolute pressure range of $0-0.1 \mathrm{MPa}$ corresponding to the relative pressure of $0<p / p_{0} \leq 0.996$. Nitrogen $\left(\mathrm{N}_{2}\right)$ was used as adsorbate in the temperature of $77 \mathrm{~K}\left(-196^{\circ} \mathrm{C}\right)$, which partially filled the micropores and mesopores (0.001-0.2 $\mu \mathrm{m})$.

The Langmuir monolayer adsorption theory was used to characterise the micropores in the dolomite in the relative pressure range of $0.01<p / p_{0} \leq 0.70$. The theory presupposes that a monolayer of adsorbate particles forms on a energetically homogeneous surface of the sorbent. And the amount of the adsorbate is determined by the following formula:

$a=a_{\mathrm{m}} \times \frac{K \times p}{1+K \times p}$,

where $a\left(\mathrm{~cm}^{3} / \mathrm{g}\right)$ is the extent of adsorption corresponding to the filling of monolayer, $a_{\mathrm{m}}\left(\mathrm{cm}^{3} / \mathrm{g}\right)$ is monolayer capacity, $K(-)$ is adsorption equilibrium constant, $p(\mathrm{~Pa})$ is the equilibrium pressure of the adsorbed gas.

The Barrett-Joyner-Halenda (BJH) theory was used to describe the mesoporous texture of the dolomite (Barrett et al. 1951). In the relative pressure range of $0.1<p /$ $p_{0} \leq 0.996$, we determined the total volume of the pores in which capillary condensation occurs as well as the pore size distribution as a function of their diameter. The BJH model is based on the Kelvin equation (Klobes et al. 2006):

$\ln \left(\frac{p_{\mathrm{kr}}}{p_{\mathrm{s}}}\right)=-\left(\frac{2 \times \gamma \times \vartheta \times \cos \theta}{R \times T \times r_{\mathrm{m}}}\right)$, where $p_{\mathrm{kr}}(\mathrm{Pa})$ is critical condensation pressure, $p_{\mathrm{s}}(\mathrm{Pa})$ is the compressibility of the saturated vapour of the adsorbed gas, $\vartheta\left(\mathrm{m}^{3} / \mathrm{mol}\right)$ is the molar volume of the condensed adsorbate, $R(\mathrm{~J} / \mathrm{mol} \mathrm{K})$ is gas constant, $T(\mathrm{~K})$ is temperature, $r_{\mathrm{m}}(\mathrm{m})$ is mean radius of curvature of the meniscus.

In the BJH model, the layers of the adsorbed particles are treated as an adsorption film. During capillary condensation, as the pressure increases so does the thickness of the adsorbate on the pore walls. After determining the thickness of the adsorption film and its share in total adsorption, it is possible to determine the pore volume. Because the model makes considerable simplifications, among others it assumes homogeneous shape of the pores over their entire length (cylindrical or slit-like), and their opening on both sides, the results obtained by its use can be burdened with error. Thus to verify them the BrunauerEmmett-Teller (BET) surface area analysis was used for comparison (Brunauer 1945). This model is based on an adsorption isotherm, which was determined following the obtained adsorption points according to the equation:

$a_{\mathrm{t}}=\frac{a_{\mathrm{m}} \times C \times \frac{p}{p_{0}}}{\left(1-\frac{p}{p_{0}}\right) \times\left[1+(C-1) \times \frac{p}{p_{0}}\right]}$,

where $a_{\mathrm{t}}\left(\mathrm{cm}^{3} / \mathrm{g}\right)$ is the total volume of the adsorbed gas under pressure $p, p / p_{0}(-)$ is the relative pressure for the experimentally determined adsorption isotherm, $C(-)$ is the adsorption equilibrium constant dependent on the difference between the adsorption heat of the first monolayer and the condensation heat.

The adsorption equilibrium constant $C$, represented graphically, was determined from the constants of the adsorption isotherm equation. Knowing the surface covered by the adsorbate particle in the monolayer, it was possible to determine the surface area $S_{\mathrm{BET}}$ of the adsorbent from the following equation:

$S_{\mathrm{BET}}=a_{\mathrm{m}} \times \omega \times N_{\mathrm{A}}$,

where $a_{\mathrm{m}}(\mathrm{mol} / \mathrm{g})$ is molar monolayer capacity, $\omega\left(\mathrm{nm}^{2}\right)$ is the surface covered by a single particle of the adsorbate in the monomolecular layer, so-called molecular cross-sectional area, $N_{\mathrm{A}}\left(\mathrm{mol}^{-1}\right)$ is Avogadro's number.

AccuPyc II 1340 (Micromeritics) analyser was used to determine the skeletal (helium) and real density of the dolomite. The analyses allowed to measure its pores with diameters larger or equal to $2 \times 10^{-4} \mu \mathrm{m}$. The helium density was calculated based in the skeletal volume of the sample by measuring the amount of helium (He) that intruded into the open pores of the lump sample. In the temperature of $298 \mathrm{~K}$, the helium was practically inert hence its interactions with the surface of the sample were disregarded. Real density, taking into account the closed 
pores, was determined using the helium method. Before the measurement, the sample was ground in an original device (Kudasik et al. 2014) and outgassed. Grinding resulted in the opening of most of the closed pores in the dolomite.

The apparent density was determined by quasi-liquid pycnometry on GeoPyc 1360 analyser (Micromeritics). Before the measurement, the samples were crushed to particles of irregular shapes with the diameter of about 20-30 $\mathrm{mm}$. The analysis involved the measurement of the apparent volume of the sample in dry conditions using the so-called dry fluid (DryFlo). The reference volume of the chamber filled with dry fluid was determined. Subsequently, the sample of a known mass was placed in the chamber and the volume of the chamber together with the sample was identified. The volume of the sample was determined based on the difference between the volume of the empty chamber and the volume of the chamber containing the sample. The measurement cycle was repeated a few times. Knowing the real density, helium and skeletal density it was possible to calculate the total porosity as well as the porosity including the closed porosity and the total pore volume using the following formulas:

$\emptyset_{\mathrm{r}}=\frac{\rho_{\mathrm{r}}-\rho_{\mathrm{e}}}{\rho_{\mathrm{r}}} \times 100 \%$

$\emptyset_{\mathrm{c}}=\emptyset_{\mathrm{r}}-\frac{\rho_{\mathrm{sk}}-\rho_{\mathrm{b}}}{\rho_{\mathrm{sk}}} \times 100 \%$

$V_{\mathrm{t}}=\frac{\rho_{\mathrm{r}}-\rho_{\mathrm{e}}}{\rho_{\mathrm{r}} \times \rho_{\mathrm{e}}}$

where $\emptyset_{\mathrm{r}}(\%)$ is real porosity, $\emptyset_{\mathrm{c}}(\%)$ is closed porosity, $V_{\mathrm{t}}\left(\mathrm{cm}^{3} / \mathrm{g}\right)$ is total pore volume (open and closed), $\rho_{\mathrm{r}}\left(\mathrm{g} / \mathrm{cm}^{3}\right)$ is real density, $\rho_{\mathrm{e}}\left(\mathrm{g} / \mathrm{cm}^{3}\right)$ is envelope density, $\rho_{\text {sk }}\left(\mathrm{g} / \mathrm{cm}^{3}\right)$ is skeletal density.

\section{Results}

The description of the dolomites consisted of a petrographic analysis and determination of parameters defining their porous nature, i.e. porosity, surface area, pore volume and mean pore size distribution. A number of methods were used for that purpose: microscopic stereological (MS) and microcomputed tomography (Micro-CT) analyses, porosimetric (MIP, LPNA) as well as densitometric (Picno. He, DryFlo). Each of the methods represented a different approach and focused on a different size range of the pores in the dolomite. Figure 3 presents the measurement ranges analysed by the employed methods in relation to the pore classification according to IUPAC (Rouquérol et al. 1994).

\section{Petrographic description}

Petrographic analyses were carried out by a polarising microscope in transmitted light using thin sections saturated with light blue resin for contrast.

The analysed rocks comprised epigenetic dolomites, sparites (D3, D5) and fine sparites (D1, D2, D4). According to Dunham (1962), they are classified as crystal carbonates whose primary structures are unrecognisable. They occur in the form of hipautomorphic crystals, less frequently in the form of automorphic crystals. Various amounts of irregular concentrations of sulphate minerals (anhydrite and gypsum) as well as scattered opaque ore minerals causing mineralisation of those sediments and brownish black organic substance. Also relic calcite grains, often those that underwent secondary micritisation, occur in the rock.

Dolomite D1 has disordered, massive structure. The crystals are of the size of about $0.04-0.15 \mathrm{~mm}$ and are closely adjacent to one another. Small pores and fissures can be seen in places. Embedded in the rock are numerous sulphate minerals in the form of coarse-grained clusters or veins of various courses. The structure of sample D2 is disordered, slightly porous and cracked. The crystals are closely adjacent to one another and between them there are a few pores of the size in the range of $0.02-0.10 \mathrm{~mm}$. In places, the rock is filled with crystallised, micritic clusters of carbonates and streaks filled mostly with anhydrite and gypsum. In the slightly porous and disordered structure of dolomite D3, there are cracks, which are in parts filled with sulphates and organic substance. The crystals occur in various form (plates, fan-shaped, needles), and their size is up to $1 \mathrm{~mm}$. Between them, there are pores of the size from 0.01 to $0.40 \mathrm{~mm}$. Sulphate crystals are embedded in parts of the porous structure of the rock in a considerable amount (up to 10\%). The rock D4 has a slightly directional and porous structure. It is built of closely adjacent dolomite crystals the size of about $0.02-0.05 \mathrm{~mm}$. It contains a lot of pores of the size from 0.01 to $0.10 \mathrm{~mm}$ and cracks oriented in accordance with the lamination. Brownish organic material, scattered all over the surface of the sample was also observed. Dolomite D5 has the highest porosity of all the samples. Its structure is compact, disordered, without cracks, and it has intercrystalline pores. The size of the pores is in the $0.01-0.40 \mathrm{~mm}$. The sample is built of dolomite crystals of the size from 0.01 to $0.10 \mathrm{~mm}$. Between them, there are sulphate crystals of various habit and the size of up to $1 \mathrm{~mm}$. Single micrite grains were also found as well as disorderly scattered organic substance, which gives the rock a brown colour. Figure 4 presents parts of the coloured thin section of dolomites D1-D5 used for the analyses. 
Fig. 3 Determination of pore size distribution (own study)

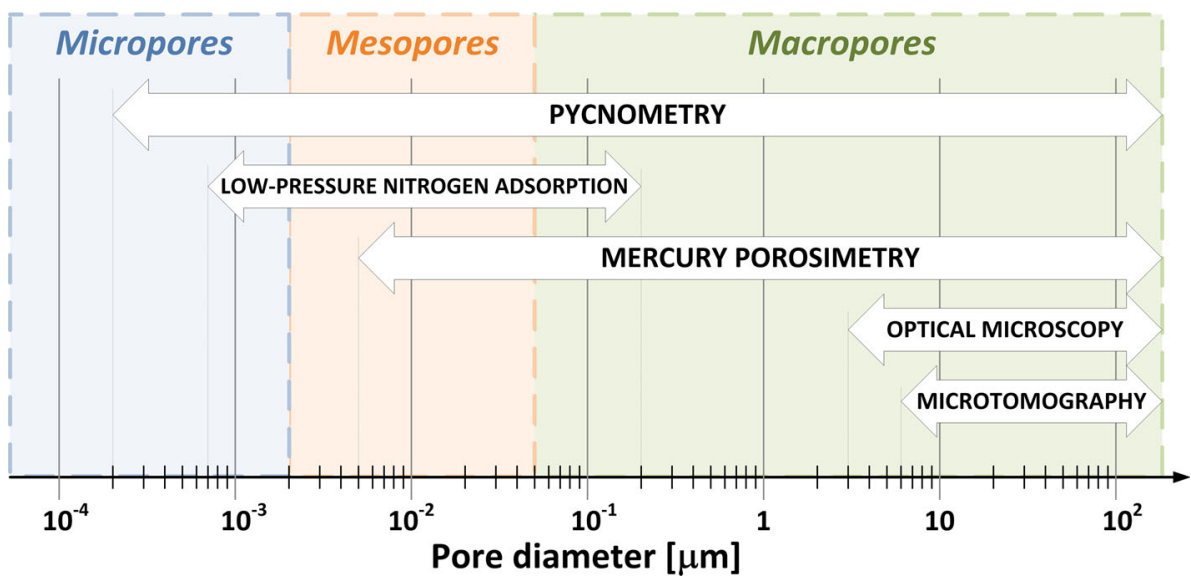

\section{Microscopic stereological analyses (MS) and computed microtomography (Micro-CT)}

The microscopic stereological analyses allowed to assess the total and open porosity of the dolomite samples. To estimate the open porosity, we used thin sections of the rock samples saturated with coloured resin, which filled the open pores visible to the microscope. Those analyses were carried out using an optical microscope and without polarisation. The images in Fig. 4, taken by PPL method, show open pores. To estimate the total porosity of the samples, we used microscopic analyses in reflected light on the surface of the polished sections. Figure 5 presents parts of the polished sections used for the stereological analyses.

Total porosity of the dolomite (open and closed) was determined using the quantitative point counting analysis, which is presented in Table 1. Before the analyses, the required number of measurement points for each sample was specified (coloured cut and polished section). Using formula (1), it was calculated that 2500 points lying in the square grid should be used for the analysis.

The MS analysis showed that open pores were predominant in all of the dolomites. The total porosity changed in the 4.8-22.9\% range. Sample D5 had the highest total porosity where closed pores made up for $1 / 3$ of the total. Samples D1 and D2 had similar amounts of closed and open pores. The smallest share of closed pores, at a level of $15.4 \%$, was in sample D3. That rock had also low total porosity $(6.6 \%)$.

The samples with extreme values of total porosity (D1 and D5) were subjected to Micro-CT analyses. The distinguished pores were divided into classes of various volume ranges, and the percentage share of those classes in the total porosity was determined (Table 2). Figure 6 shows histograms of pore numbers falling into a particular volume class as well as the volume of a given class expressed in voxels-the volume of a single voxel about $6 \mu \mathrm{m} \times 6 \mu \mathrm{m} \times 6 \mu \mathrm{m}$.
The share of pore volume of class 3 and 4 (over 30\% each) and the number of pores of class 1 and 2 were predominant in samples D1 and D5. The porous dolomite D5 had almost one order of magnitude higher pore volume in all the classes as compared to dolomite D1. It also had large volume pores from class 6 , which were not present in dolomite D1. The largest volume pores from class 7 were not present in either of the samples (Table 2). Example microtomography analysis of the pore structure in dolomite D5 was presented in Fig. 7.

\section{Porosimetric analyses}

The studies included the analyses of mercury intrusion into the porous structures under high-pressure (MIP) as well as low-pressure nitrogen adsorption in a temperature of $77 \mathrm{~K}$ (LPNA). The LPNA method was used to determine the dolomite pore structure focusing on micropores and part of mesopores $(0.001 \mu \mathrm{m} \geq D \geq 0.020 \mu \mathrm{m})$. The measurements yielded experimental points of adsorption and desorption isotherms (Fig. 8). All the isotherms were of similar shape and according to IUPAC guidelines (IUPAC 1982) they were classified as III type isotherms typical of non-porous and macroporous materials.

The ability of dolomite to adsorb nitrogen in the pressure range from 0 to $0.1 \mathrm{MPa}$ varied. Samples D1 and D3 had the highest sorption capacity, which was at the level of 3.6 and $3.3 \mathrm{~cm}^{3} / \mathrm{g}$, respectively. The sorption capacity of the other samples was from 1.6 to $2.0 \mathrm{~cm}^{3} / \mathrm{g}$.

Knowing the amount of the adsorbed gas and using the linear form of the BET equation (Fig. 9), it was possible to determine the surface area of the dolomites assuming that the molecular cross-sectional area $\left(\mathrm{N}_{2}\right)$ equalled $0.162 \mathrm{~nm}^{2}$.

Table 3 presents the results of the porosimetric analyses. The values of the structural parameters in the LPNA method using BET and BJH models were convergent. Samples D1 and D2 had the highest value of the surface 
Fig. 4 Dolomites D1-D5, coloured thin section, transmitted light; $P P L$ plain polarized light, $C P L$ crossed polarized light
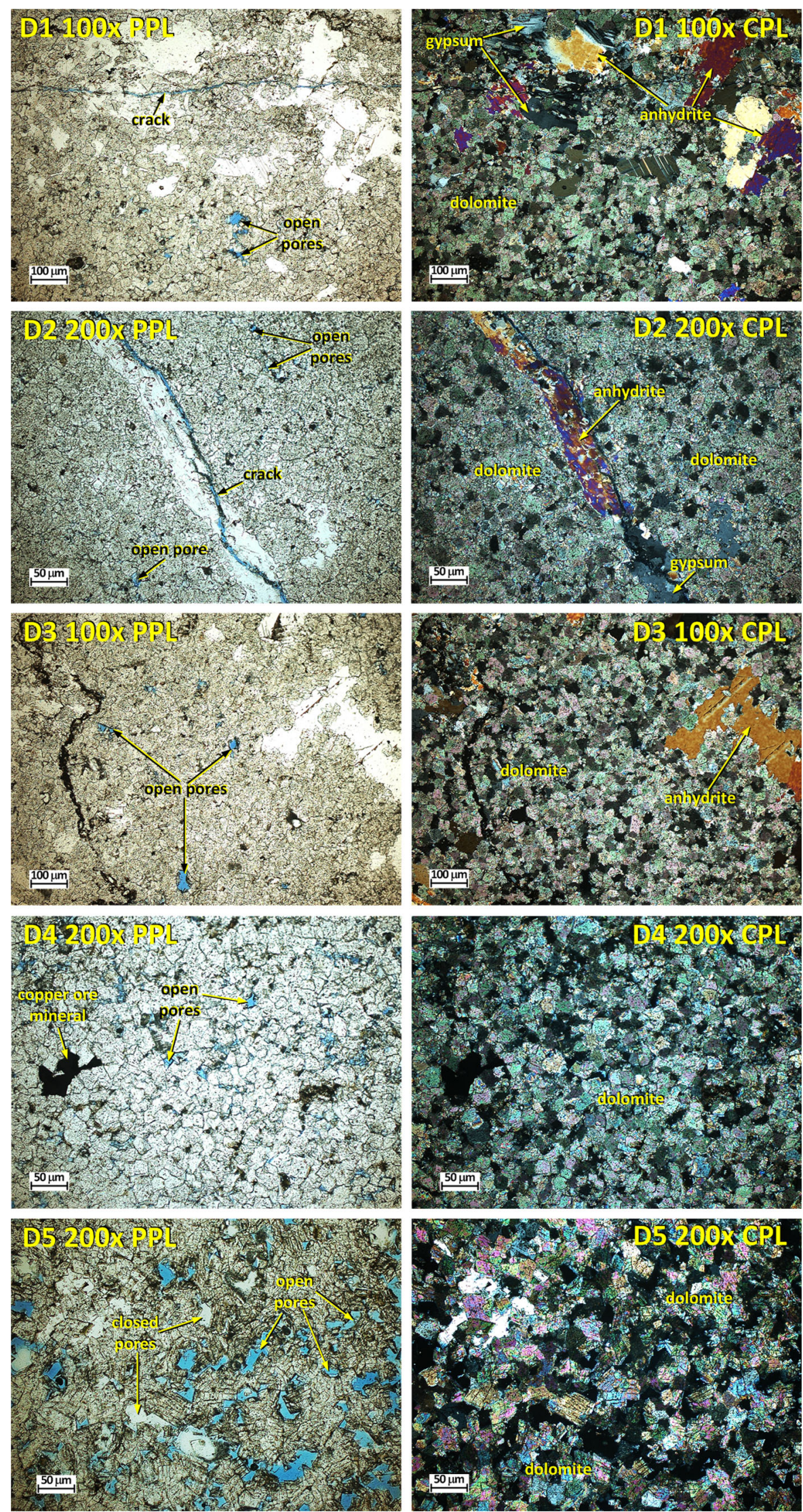

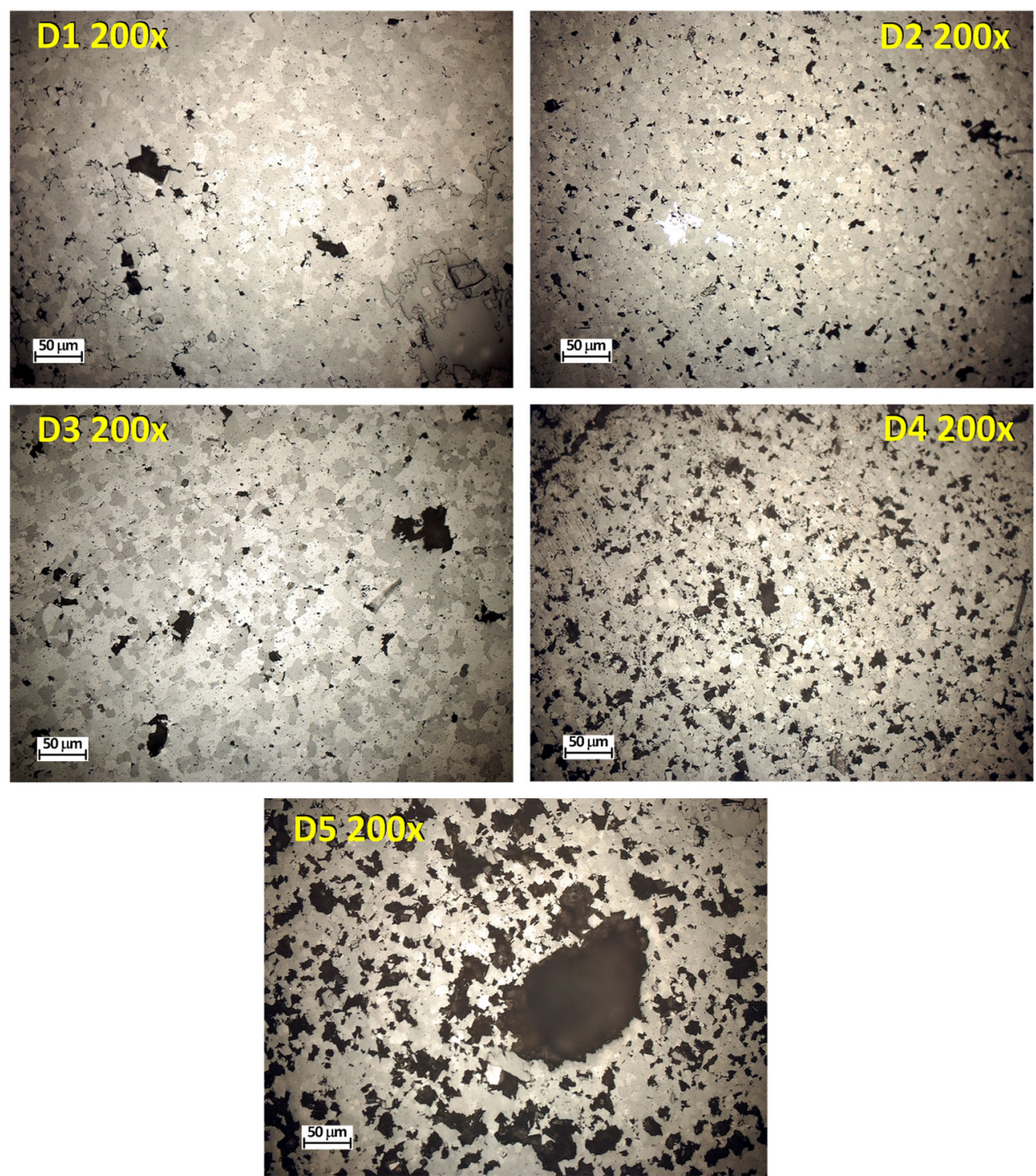

Fig. 5 Dolomites D1-D5, polished section. Black and dark grey areas-pores. Reflected light

Table 1 Quantitative point counting analysis of the dolomite samples

\begin{tabular}{lcccccc}
\hline Sample symbol & Unit & D1 & D2 & D3 & \multicolumn{1}{c}{ D4 } & \multicolumn{1}{c}{ D5 } \\
\hline Quantitative point counting & analysis & & & & \\
Total porosity & $\%$ & 4.75 & 9.70 & 6.56 & 12.70 & 22.87 \\
Open porosity & $\%$ & 2.81 & 5.19 & 5.55 & 8.22 & 14.67 \\
Open pores share & $\%$ & 59.16 & 53.51 & 84.60 & 64.72 & 64.15 \\
Closed pores share & $\%$ & 40.84 & 46.49 & 15.40 & 35.28 & 35.85 \\
\hline
\end{tabular}

Table 2 The pore structure of dolomites D1 and D5 (Micro-CT method)

\begin{tabular}{llllr}
\hline Class number & $\begin{array}{l}\text { Class volume, } \\
\text { voxel }\end{array}$ & Unit & \multicolumn{2}{c}{ Class share } \\
\cline { 4 - 5 } & & & D1 & D5 \\
\hline Computed tomography & $\%$ & 16.3 & 2.1 \\
1 & $1-9$ & $\%$ & 17.3 & 15.7 \\
2 & $10-99$ & $\%$ & 31.9 & 36.2 \\
3 & $100-999$ & $\%$ & 32.7 & 35.8 \\
4 & $1000-9999$ & $\%$ & 1.8 & 8.4 \\
5 & $10,000-99,999$ & $\%$ & 0.0 & 1.9 \\
6 & $100,000-399,999$ & $\%$ & 0.0 & 0.0 \\
7 & $>400,000$ & & & \\
\hline
\end{tabular}



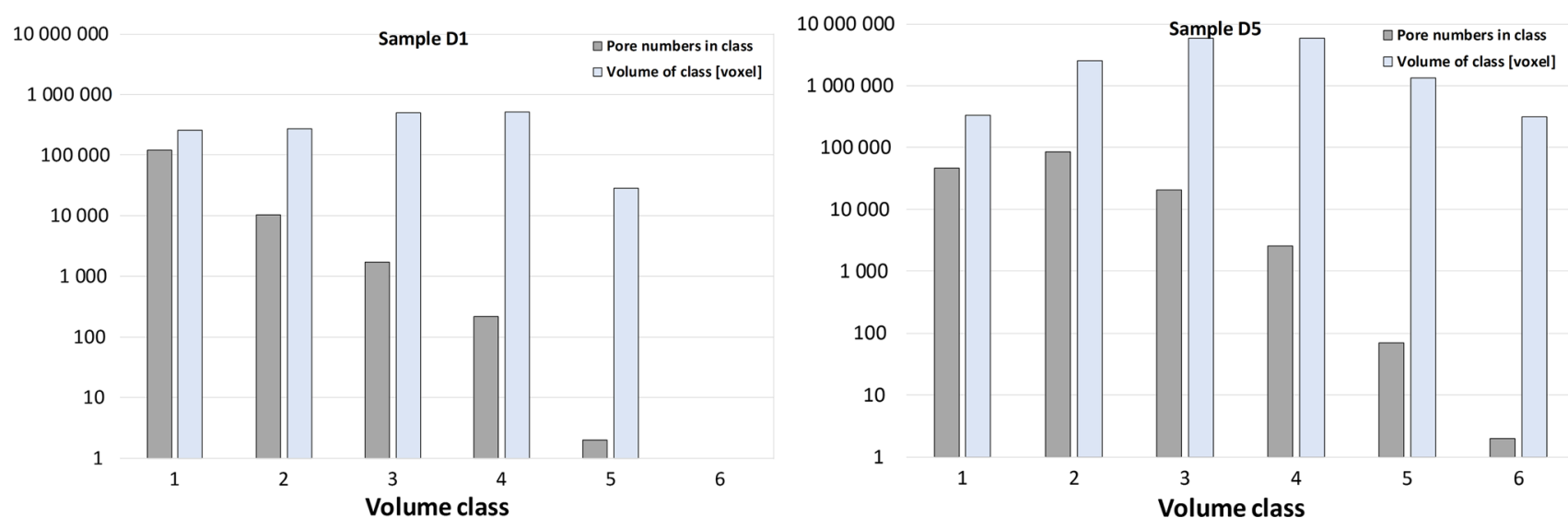

Fig. 6 Quantitative and volumetric characteristics of the pores in dolomites D1 and D5 (Micro-CT method)
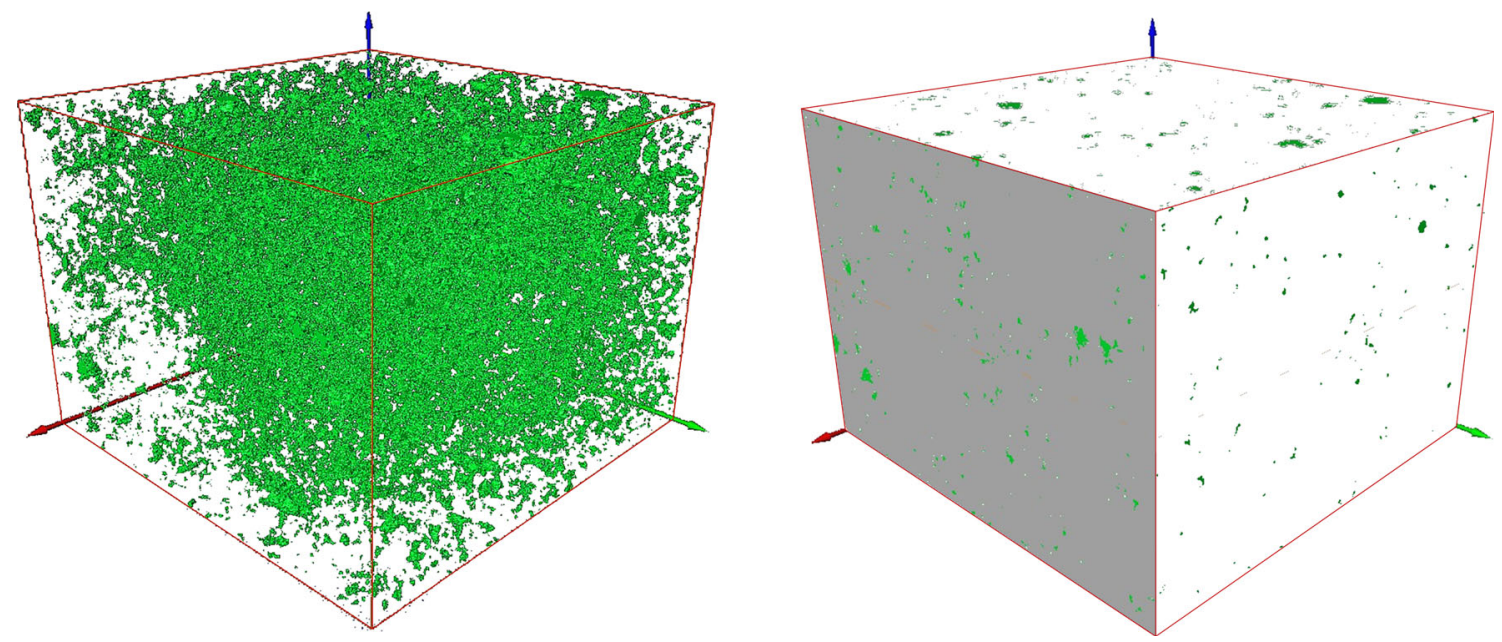

Fig. 7 Microtomography of the pore structure in dolomite D5 (Micro-CT method)

Fig. 8 Adsorption and desorption isotherms of the dolomite samples (LPNA method)

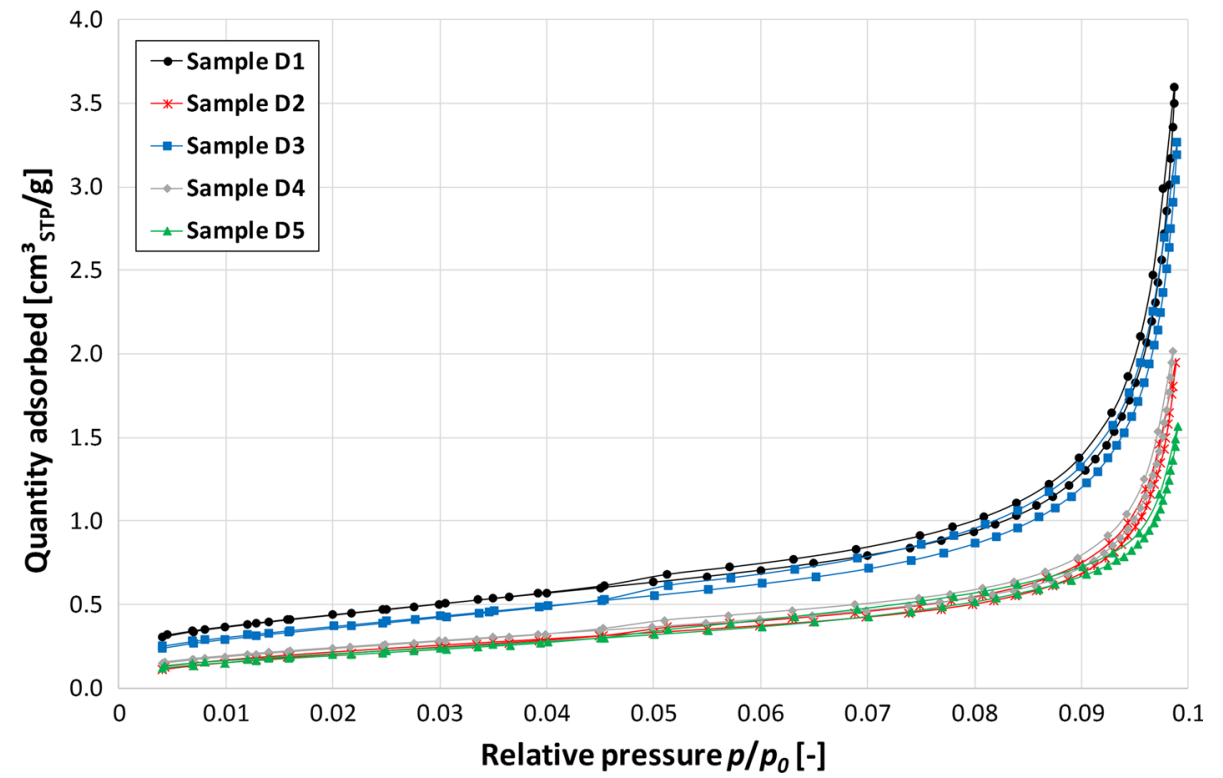


Fig. $9 \mathrm{~N}_{2}$ adsorption isotherms as a point function of the linear form of the BET equation
Table 3 Porosimetric characteristics of dolomite (LPNA, MIP methods)

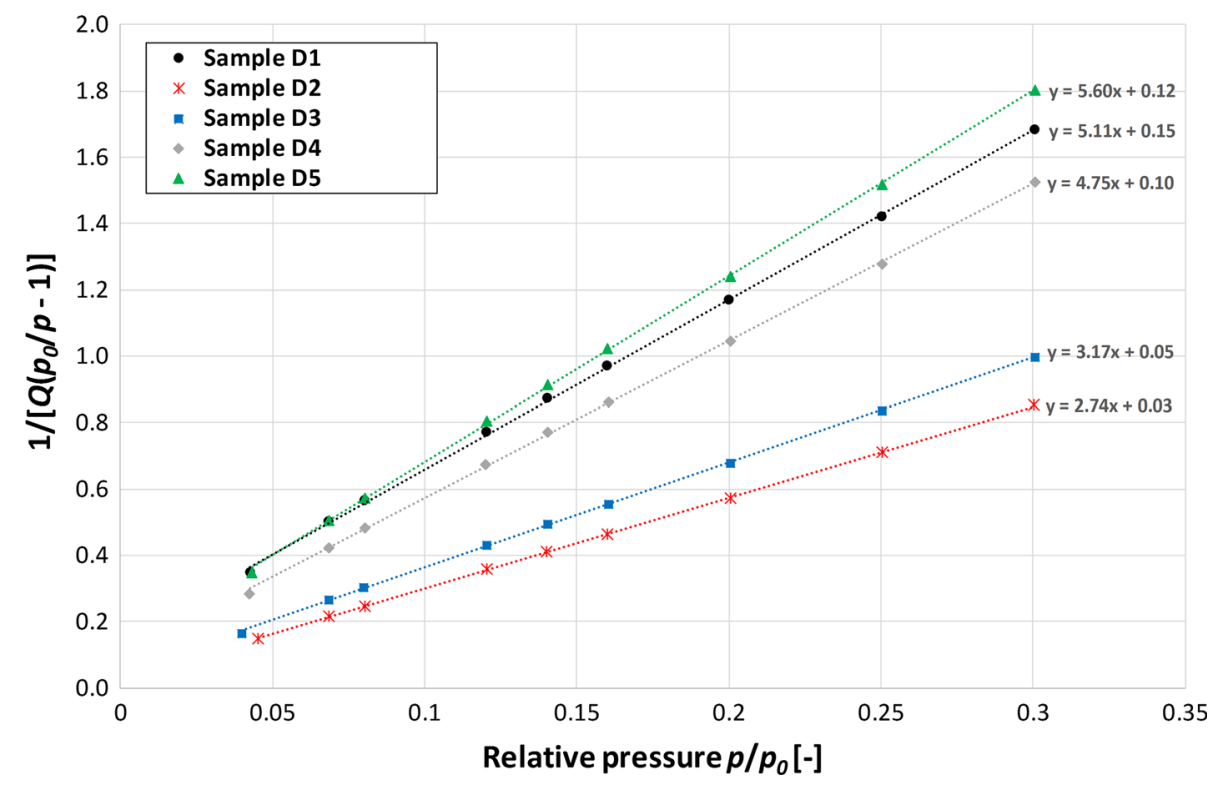

\begin{tabular}{lllllll}
\hline & Unit & \multicolumn{2}{l}{ Sample symbol } & & \\
\cline { 3 - 7 } & & $\mathrm{D} 1$ & $\mathrm{D} 2$ & $\mathrm{D} 3$ & $\mathrm{D} 4$ & $\mathrm{D} 5$ \\
\hline Gas adsorption $(\mathrm{N} 2,77 \mathrm{~K})$ & & & & & & \\
Sorption capacity & $\mathrm{cm}^{3} / \mathrm{g}$ & 3.60 & 1.95 & 3.27 & 2.02 & 1.56 \\
Surface area Langmuir & $\mathrm{m}^{2} / \mathrm{g}$ & 2.45 & 1.35 & 2.12 & 1.43 & 1.21 \\
Single point surface area BET & $\mathrm{m}^{2} / \mathrm{g}$ & 1.53 & 0.78 & 1.31 & 0.86 & 0.73 \\
Surface area BET & $\mathrm{m}^{2} / \mathrm{g}$ & 1.58 & 0.83 & 1.36 & 0.90 & 0.76 \\
Pore volume BET & $\mathrm{cm}^{3} / \mathrm{g}$ & 0.005 & 0.002 & 0.004 & 0.002 & 0.002 \\
Mean pore diameter BET & $\mu \mathrm{m}^{2}$ & 0.012 & 0.013 & 0.013 & 0.011 & 0.011 \\
Surface area BJH & $\mathrm{m}^{2} / \mathrm{g}$ & 1.53 & 0.84 & 1.47 & 0.94 & 0.84 \\
Pore volume BJH & $\mathrm{cm}^{3} / \mathrm{g}$ & 0.005 & 0.003 & 0.005 & 0.003 & 0.002 \\
Mean pore volume BJH & $\mathrm{cm}^{3} / \mathrm{g}$ & 0.013 & 0.013 & 0.013 & 0.013 & 0.011 \\
Mercury porosimetry $(\mathrm{Hg})$ & & & & & & \\
Surface area & $\mathrm{m} / \mathrm{g}$ & 0.25 & 0.53 & 0.37 & 0.32 & 0.07 \\
Open pore volume & $\mathrm{cm}^{3} / \mathrm{g}$ & 0.002 & 0.017 & 0.012 & 0.001 & 0.020 \\
Skeletal density & $\mathrm{g} / \mathrm{cm}^{3}$ & 2.77 & 2.88 & 2.85 & 2.88 & 2.52 \\
Bulk density & $\mathrm{g} / \mathrm{cm}^{3}$ & 2.76 & 2.75 & 2.76 & 2.79 & 2.40 \\
Open porosity & $\%$ & 0.61 & 4.63 & 3.23 & 3.00 & 4.84 \\
Mean pore diameter & $\mu \mathrm{m}^{2}$ & 0.103 & 0.094 & 0.117 & 0.105 & 0.117 \\
\hline & & & & & &
\end{tabular}

area (nearly $1.5 \mathrm{~m}^{2} / \mathrm{g}$ ), total volume of micropores and part of open mesopores $\left(0.004-0.005 \mathrm{~cm}^{3} / \mathrm{g}\right)$. In samples D2 and D5 those values were $50 \%$ lower. The mean pore diameter in all the dolomites was similar (0.011-0.013 $\mu \mathrm{m})$.

According to the MIP analysis, the surface area of the macropores and part of the mesopores in the $0.005 \mu \mathrm{m} \leq D \leq 100 \mu \mathrm{m}$ range was below $1 \mathrm{~m}^{2} / \mathrm{g}$ (Table 3). The total open pore volume was in the range of $0.001-0.020 \mathrm{~cm}^{3} / \mathrm{g}$ and the open porosity $1-5 \%$. Dolomites D2 and D5 had the highest porosity and the pore volume, whereas in dolomite D1 those parameters were the lowest.

Figure 10 presents a juxtaposition of the pore size distributions and the cumulative pore volumes in the dolomites determined using MIP and LPNA methods. Macropores were dominant in the pore volume of all the samples. Dolomites D2, D4 and D5 had the highest cumulative volume in the range of macropores and the lowest cumulative volume in the range of micro- and mesopores (LPNA). Macropores in the diameter range of $0.03-0.90 \mu \mathrm{m}$ predominated in dolomites D2 and D4 and 

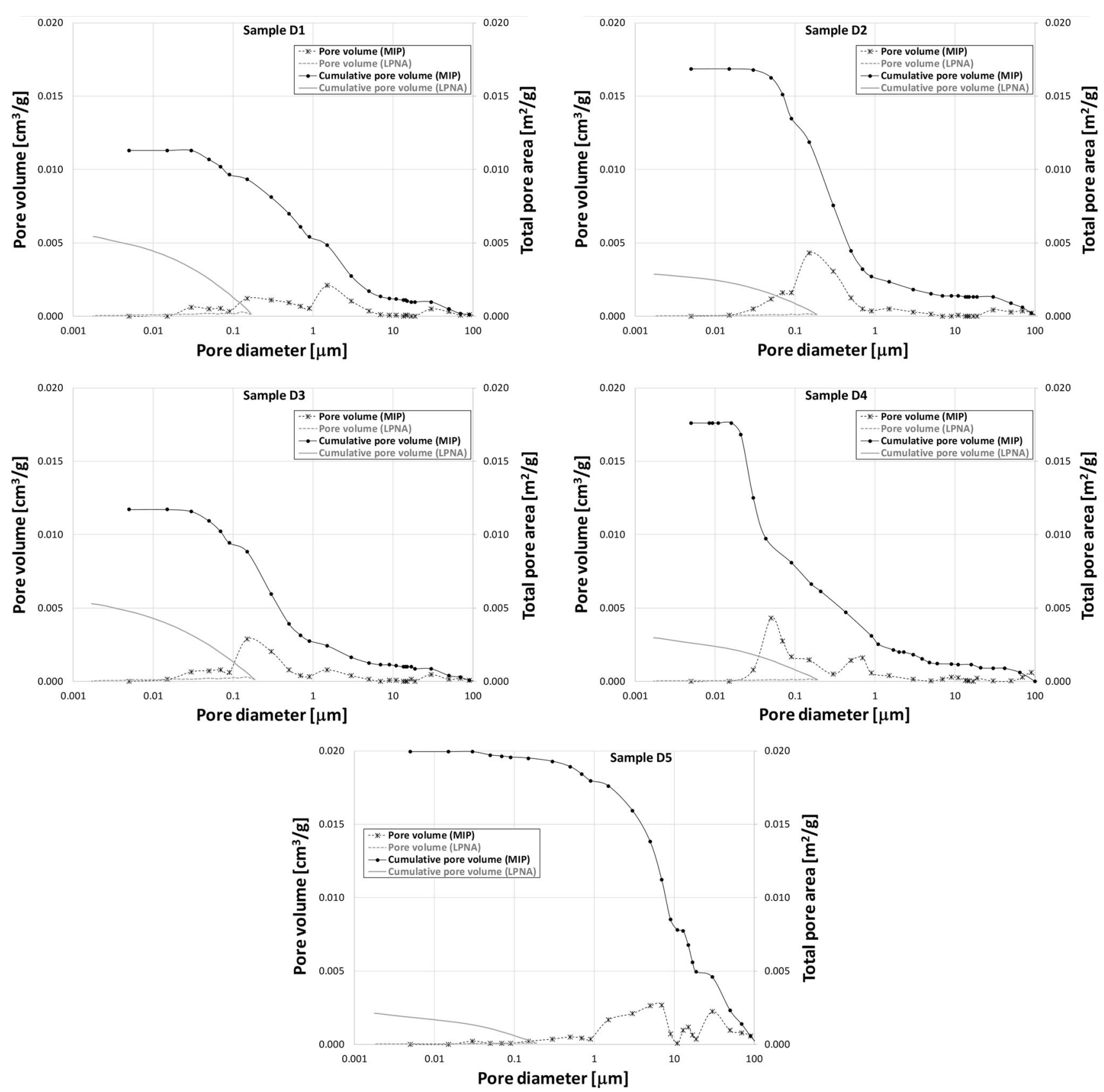

Fig. 10 Pore size distribution (PSD) and cumulative pore volume as a function of pore sizes (MIP and LPNA methods)

the 1-70 $\mu \mathrm{m}$ in dolomite D5. Dolomites D1 and D3 had a lower volume in the range of macropores (MIP) and a higher volume in the range of micro and part of mesopores (LPNA) as compared to the other dolomites (Table 4).

\section{Densitometric analysis}

The densitometric analyses showed that the total porosity in all the samples was between 10 and $20 \%$ and the open porosity predominated. The highest value of the total porosity was obtained in dolomites D4 and D5 (18\%), which also had much higher open porosity than the other samples. Sample D1 had the lowest total porosity and the smallest percentage of closed pores.

\section{Discussion}

To evaluate the convergence of the selected measurement methods the parameters obtained by the use of those methods were compared. Figure 11 shows the values of the total, open and closed porosity of the dolomites determined 
Table 4 Densitometric analysis of dolomite

\begin{tabular}{llccccc}
\hline & Unit & \multicolumn{2}{l}{ Sample symbol } & & \\
\cline { 5 - 7 } & & $\mathrm{D} 1$ & $\mathrm{D} 2$ & $\mathrm{D} 3$ & $\mathrm{D} 4$ & $\mathrm{D} 5$ \\
\hline Pycnometry (He, DryFlo) & & & & & & \\
Real density & $\mathrm{g} / \mathrm{cm}^{3}$ & 2.90 & 2.98 & 2.97 & 2.89 & 2.96 \\
Skeletal density & $\mathrm{g} / \mathrm{cm}^{3}$ & 2.84 & 2.86 & 2.89 & 2.79 & 2.85 \\
Bulk density & $\mathrm{g} / \mathrm{cm}^{3}$ & 2.57 & 2.63 & 2.58 & 2.36 & 2.43 \\
Pore volume & $\mathrm{cm}^{3} / \mathrm{g}$ & 0.039 & 0.048 & 0.051 & 0.052 & 0.075 \\
Total porosity & $\%$ & 11.38 & 11.96 & 13.13 & 18.34 & 17.91 \\
Open porosity & $\%$ & 9.51 & 7.99 & 10.73 & 15.41 & 14.74 \\
Closed porosity & $\%$ & 1.87 & 3.98 & 2.40 & 2.93 & 3.17 \\
Open pores share & $\%$ & 83.55 & 66.75 & 81.69 & 84.04 & 82.30 \\
Closed pores share & $\%$ & 16.45 & 33.25 & 18.31 & 15.96 & 17.70 \\
\hline
\end{tabular}

Fig. 11 Juxtaposition of the parameters of the total and open porosity determined by MS and Pycno. methods

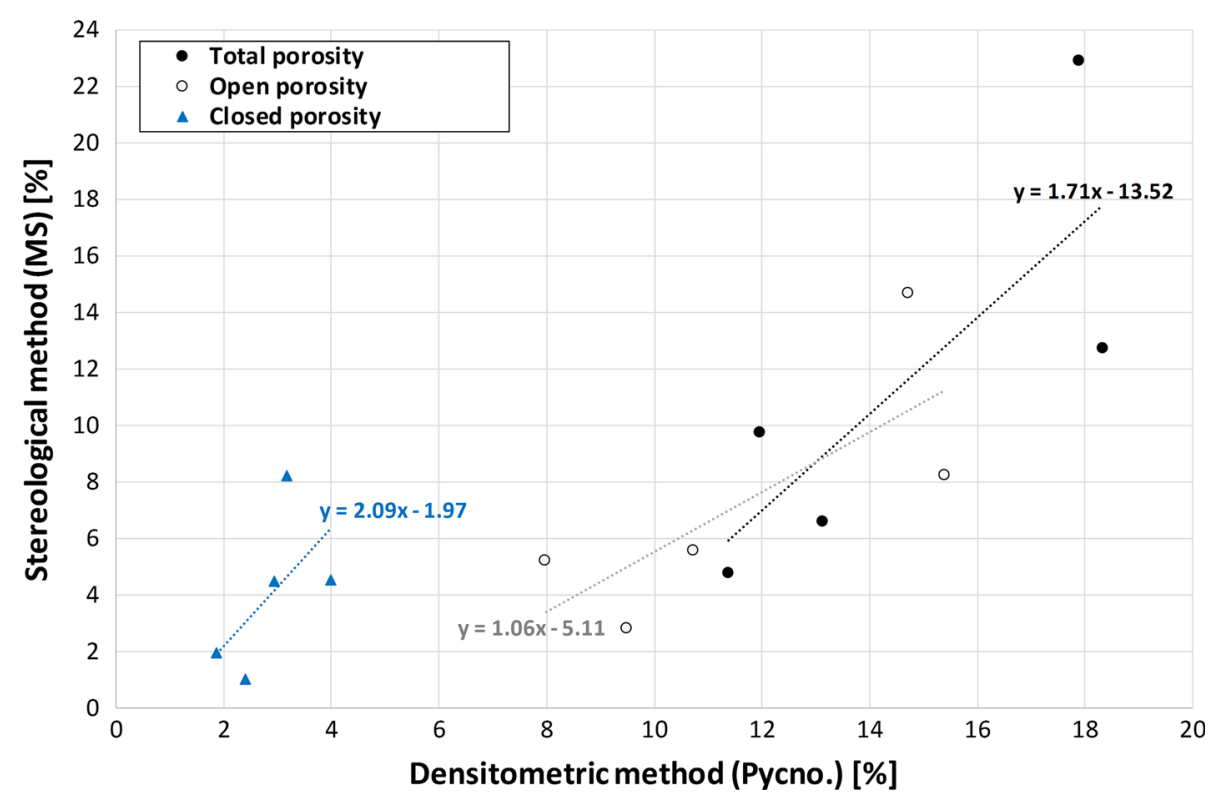

by the MS and Pycno. methods. The values of the total and the open porosity parameters were higher in most samples when using the Pycno. method rather than the MS method. It was due to the fact that the Pycno. method was used to analyse a broader size range of the pores, which was in the range from $2 \times 10^{-4} \mu \mathrm{m}$, whereas in the case of the MS method it started from $3 \mu \mathrm{m}$. In spite of the different range of the pore size measured by the two methods, they yielded a similar changing trend of the porosity in all the dolomites, which is indicative of the convergence of the results.

Figure 12 presents a comparison of the open porosity parameters determined by the MS method with the porosity, volume and mean pore diameter determined by the MIP method. Both methods analysed macropores. However, the measurement range of the MIP method was much broader as it covered the pores with the diameter size from $0.005 \mu \mathrm{m}$. Despite different size ranges, it was observed that the porosity values (MS, MIP) were convergent. The dolomites of the highest porosity had also a larger volume and a larger mean diameter of macro and mesopores (MIP).

The LPNA and Pycno. methods were used to determine porosity taking into account the smallest forms-micropores. The size range of the analysed pores varied and depended on the measurement method used. Whereas the LPNA method was used to characterise pores with diameters up to $0.02 \mu \mathrm{m}$, the Pycno. method analysed the full range of porosity. Figure 13 presents the measurements of the sorption capacity, surface area BET and mean pore diameter (LPNA method) with the open porosity of the dolomites (Pycno. method). It was observed that as the porosity increases (Pycno.) the sorption capacity, the surface area BET and mean pore diameter (LPNA) decrease. Those relations indicate that the share of the micropores in the sorption capacity and the surface area (LPNA) is smaller in the case of dolomites of higher total open porosity (Pycno.). These observations are confirmed by 
Fig. 12 Juxtaposition of the porosity, volume and mean pore diameter (MIP) with the open porosity (MS)

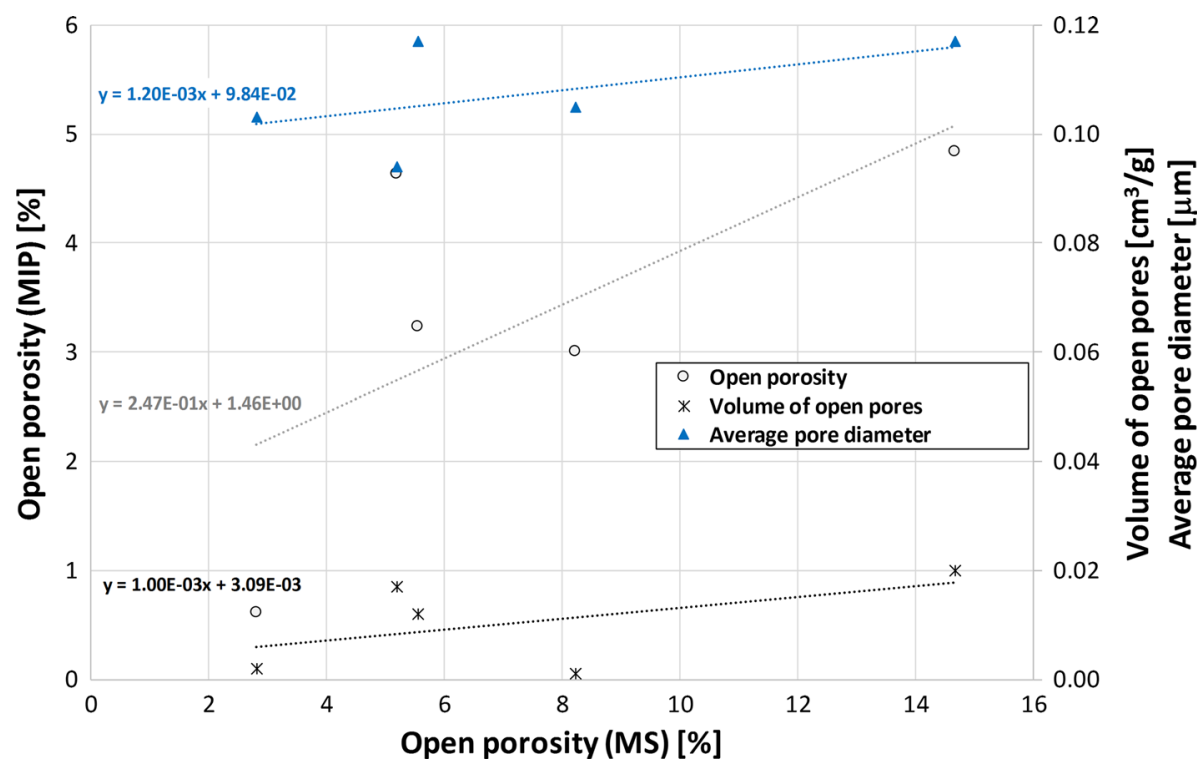

Fig. 13 Juxtaposition of sorption capacity, surface area BET and mean pore diameter (LPNA) with open porosity (Pycno.)

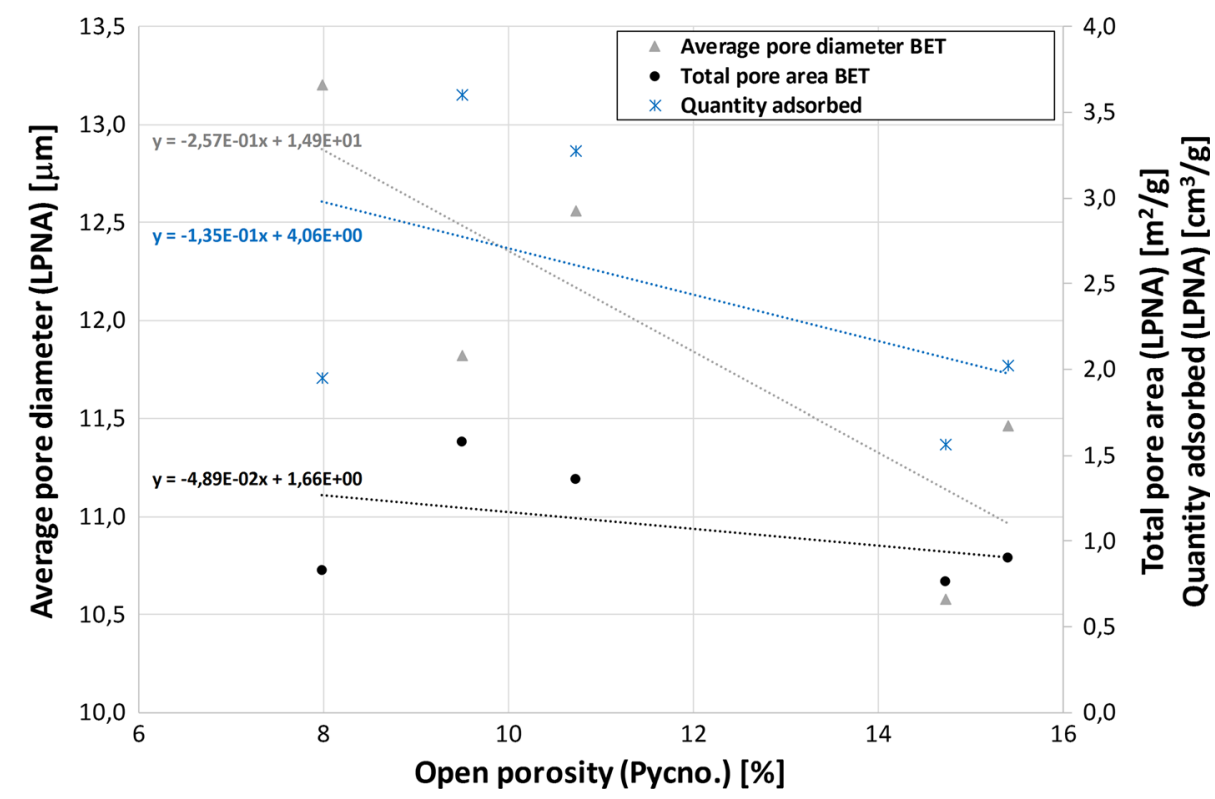

presented PSD (Fig. 10) where the dolomites of the largest pore volume had the least developed gas capacity in the range of micropores.

\section{Conclusions}

Poland holds a leading position in the world in terms of copper and silver production. The specificity of the pore space of copper-bearing rocks including dolomites from the copper mines in the Legnica-Głogów Copper Belt area is extremely important from the point of view of the efficiency and safety of the extraction of those minerals. It depends on a number of factors such as genesis of sediments, their elemental composition and broadly defined petrographic features.

The identification of the porous structure of dolomite is of utmost importance as regards the possibilities to locate those areas of mine workings that have different structural properties and thus are potentially vulnerable to gasogeodynamic hazard. This article presents the structural and textural characteristics of dolomite, determined by the use of various measurement techniques (MS, Micro-CT, MIP, LPNA, Pycno.).

The following parameters of the rocks were specified: total porosity (taking into account the division into open and closed porosity), surface area, volume and the size and the distribution of the pores. Based on the performed 
analyses, it was observed that the distribution of the pore structure of the dolomite is not homogeneous. This proved that for a full structural and textural description, it is necessary to employ a number of measurement methods. Those methods should take into account various diameter ranges of the pores in the rocks.

Petrographic analyses showed that the sediments had undergone advanced diagenetic processes. Their structural and textural features differ depending on the place from which they were extracted. It is particularly visible in the changes of porosity, but their mineral composition does not fundamentally vary. Diagenetic transformations of the sediments resulted in the modification of the rock structure, which led to the development of secondary dolomites. The porous space of those sediments also underwent a considerable modification. As a result of compaction and crystallisation of the secondary minerals, their original porosity decreased. Processes such as dissolution and recrystallisation (dolomitisation) led to the formation of quite large, secondary pores. The recrystalisation effected the formation of intercrystal porosity (Choquette and Pray 1970) with pores surrounded by sharp-edged dolomite crystals. The analysed rocks were classified as secondary dolomites (epigenetic). According to Dunham classification (Dunham 1962), they are sparites or microsparites dolomites whose original depositional structures are unrecognisable.

Comprehensive porosimetric analyses showed that dolomite rocks are characterised by high structural variability. They have mesopores and macropores but few micropores. Their structure is not homogeneous, which was determined by the use of pores size distribution.

The stereological analyses showed that the studied sediments are porous, and in places highly porous. Their total porosity varied and was in a broad range of 5-23\%. Open porosity, forming effective porosity, predominated in all the samples. Pores of the size in the range of 3-400 $\mu \mathrm{m}$ were observed. Dolomite D5 was the most porous and without cracks. It had compacted, disordered structure and large pores of the size from 10 to $400 \mu \mathrm{m}$. As the MicroCT analysis showed, it had almost one order of magnitude higher pore volume than the least porous dolomite D1, which had firm, fine-crystalline structure.

The densitometric analysis confirmed that the open porosity had the highest share in the total porosity and was in the range of $67-84 \%$. The three analysed samples: D1, D2 and D3 had the open porosity amounting to 9.5, 8.0 and $10.7 \%$, respectively. For a comparison, the open porosity of the five samples taken from the areas of Rudna copper mine that lay some distance away from the place of the outburst which took place in 2009, was from 6.5 to $10.5 \%$. Another two studied samples (D4 and D5) had open porosity of 15.4 and $14.7 \%$. The five dolomite samples extracted from the post-outburst mass after the dolomite and rock outburst in Rudna copper mine had similar porosity (from 15.6 to $16.8 \%$ ) which was determined by pycnometry (Wierzbicki and Młynarczuk 2013).

Comparing the results of the pycnometric analyses of the dolomites from Polkowice-Sieroszowice copper mine with the studies of the dolomites from Rudna coper mine, it can be concluded that samples D4 and D5 should be regarded as structurally altered. The area of the mine from which the samples were extracted may thus be prone gasogeodynamic hazard. Nevertheless, extensive porosity is not a sufficient condition for a gas and dolomite outburst to take place. It is the presence of gas contained in the pores and fissures.

Combating gasogeodynamic hazard in copper mining can include identifying those areas of the rock mass that have different structural properties as well as finding socalled gas pockets ( $\mathrm{Li}$ et al. 2003; Jiang et al. 2011; Wierzbicki and Młynarczuk 2013). The joint application of optical, porosimetric and densitometric analyses presented in this paper, allowed to obtain a complete view of the porous structure of the rocks comprising micro-, meso- and macropores. Supplementing the presented data with gas analyses of the studied rocks might provide a full insight into the risk level in copper mines.

Acknowledgements This work was funded by the National Centre for Research and Development as part of the project called "An innovative support system for gas hazard evaluation in copper ore mine" (Project No. LIDER/003/408/L-4/12/NCBR/2013).

Open Access This article is distributed under the terms of the Creative Commons Attribution 4.0 International License (http://crea tivecommons.org/licenses/by/4.0/), which permits unrestricted use, distribution, and reproduction in any medium, provided you give appropriate credit to the original author(s) and the source, provide a link to the Creative Commons license, and indicate if changes were made.

\section{References}

Alderton DHM, Selby D, Kucha H, Blundell DJ (2016) A multistage origin for Kupferschiefer mineralization. Ore Geol Rev 79:535-543

Barrett EP, Joyner LG, Halenda PP (1951) The determination of pore volume and area distribution in porous substances. I. Computations from nitrogen isotherms. J Am Chem Soc 73:373-380

Beamish B, Crosdale PJ (1998) Instantaneous outbursts in underground coal mines: an overview and association with coal type. Int J Coal Geol 35:27-55

Bolewski A, Parachoniak W (1982) Petrografia. Wydawnictwa Geologiczne, Warszawa

Brunauer S (1945) Adsorption of gases and vapors, volume 1. Physical adsorption, vol 1. Princeton University Press, Princeton

Butra J, Orzepowski S (2001) New method of high-energy seismic event precursory symptoms detection. In: Proceedings of the rockburst and seismicity in mine symposium RaSiM-5, Mount Amanzi, pp 535-542 
Cao YX, He D, Glick DC (2001) Coal and gas outbursts in footwalls of reverse faults. Int J Coal Geol 48(1-2):47-63

Choquette PW, Pray LC (1970) Geological nomenclature and classification of porosity in sedimentary cabonates. Am Asso Petrol Geol Bull 54(2):207-250

Czekański E, Kwolek K, Mikołajewski Z (2010) Hydrocarbon fields in the Zechstein Main Dolomite $(\mathrm{Ca} 2)$ on the Gorzów Block (NW Poland). Prz Geol 58(8):695-703

Díaz Aguado MB, González Nicieza C (2007) Control and prevention of gas outbursts in coal mines, Riosa-Olloniego coalfield, Spain. Int J Coal Geol 69(4):253-266

Dunham RJ (1962) Classification of carbonate rocks according to depositional texture. In: Hamm WE (ed) Classification of carbonate rocks, a symposium. American Association of Petroleum Geologists, pp 108-121

Dziedzic D, Kalisz M, Olchawa M, Serafiński M, Turkiewicz W (2007) Natural hazards in Polish copper ore mining. Cuprum Ore Min Sci Tech Mag 1:9-43

Godyń K (2016) Microscopic research of the pore space of dolomites of the Zechstein copper-bearing formation of Polkowice area. Trans Strata Mech Res Inst 18(3):43-53

Hargraves AJ (1983) Instantaneous outbursts of coal and gas: a review. Proc Australas Inst Min Metall 285(3):1-37

Harvey TJM, Cory S, Kizil MS, Gillies S (1998) Mining through $\mathrm{H}_{2} \mathrm{~S}$ seam gas zones in underground coal mines. In: Proceedings, Council of Mining and Metallurgical Institutions Congress, Montreal. Canadian Institute of Mining, Metallurgy and Petroleum, Toronto

IUPAC (1982) Physical Chemistry Division, Commission on Colloid and Surface Chemistry Including Catalysis, Subcommittee on reporting gas adsorption data. Reporting physisorption data for gas/solid systems with special reference to the determination of surface area porosity. Pure Appl Chem 54:11

Jiang JY, Cheng YP, Wang L, Li W, Wang L (2011) Petrographic and geochemical effects of sill intrusions on coal and their implications for gas outbursts in the Wolonghu Mine, Huaibei Coalfield, China. Int J Coal Geol 88(1):55-66

KGHM Polska Miedź S.A. (2016) Official web page. www.kghm. com

Kijewski P, Kubiak J, Gola S (2012) Hydrogen sulfide—a new threat in copper ore mining. Bull Miner Energy Econ Res Inst Pol Acad Sci 83:83-95

Klobes P, Meyer K, Munro RG (2006) Porosity and specific surface area measurements for solid materials. Special publication. NIST recommended practice guide. NIST, Gaithersburg

Konopacka Ż, Zagożdżon KD (2014) Łupek miedzionośny LegnickoGłogowskiego Okręgu Miedziowego. Drzymała J, Kowalczuk PB (eds) WGGG PWr 7-12

Książkiewicz M (1979) Geologia Dynamiczna. Wydawnictwo Geologiczne, Warszawa

Kudasik M, Skoczylas N, Murzyn T, Wierzbicki M (2014) The effectiveness of the rock comminution process in the light of evaluating gas content in rocks. Trans Strata Mech Res Inst 16(3-4):81-84

Lama RD, Bodziony J (1996) Outbursts of gas. Coal and rock in underground coal mines. R.D. Lama, Wollongong

Li H, Ogawa Y, Shimada S (2003) Mechanism of methane flow through sheared coals and its role in methane recovery. Fuel 82:1271-1279

Manecki A, Muszyński M (eds) (2008) Przewodnik do petrografii. Uczelniane Wydawnictwo Naukowo-Dydaktyczne AGH, Kraków

Mingju L, Qigen D, Zhao F, Liu Y (2012) Origin of hydrogen sulfide in coal seams in China. Saf Sci 50:4

Pajdak A, Kudasik M (2016) Structural properties of dolomite rock from copper mines. Trans Strata Mech Res Inst 18(3):3-9

Pytel W (2003) Rock mass-mine workings interaction model for Polish copper mine conditions. Int J Rock Mech Min Sci 40:497-526

Rouquérol J, Avnir D, Fairbridge CW, Everett DH, Haynes JH, Pernicone N, Ramsay JDF, Sing KSW, Unger KK (1994) Recommendations for the characterization of porous solids (technical report). Pure Appl Chem 66(8):1739-1758

Ryś J (1995) Stereology of materials. Fotobit Design, Kraków

Skoczylas N (2014) Estimating gas and rock outburst risk on the basis of knowledge and experience- the expert system based on fuzzy logic. Arch Min Sci 59(1):41-52

State Mining Authority (2012) Health and Safety in mining in 2011, Katowice. www.wug.gov.pl

State Mining Authority (2015) Evaluation of the safety, mine rescue and public safety in relation with the activities of mining and geology in 2014, Katowice

Swart PK, Wortmann UG, Mitterer RM, Malone MJ, Smart PL, Feary DA, Hine AC (2000) Hydrogen sulfide-hydrates and saline fluids in the continental margin of South Australia. Geology 28(11):1039-1042

Szlazak J (2013) The influence of natural hazards on work safety in mines. Gór Geol Wydaw Politech Śląskiej 8(1):113-123

U.S. Geological Survey (2015) Mineral commodity summaries 2015: U.S. Geological Survey 196. doi:10.3133/70140094

Washburn EW (1921) The dynamics of capillary flow. Phys Rev 17(3):273-283

Wierzbicki M, Młynarczuk M (2006) Microscopic analysis of structure of coal samples collected after a gas and coal outbursts in the gallery D-6, coal seam 409/4 in the "Zofiówka" coal mine (Upper Silesian Coal Basin). Arch Min Sci 51(4):577-588

Wierzbicki M, Młynarczuk M (2013) Structural aspects of gas and dolomite outburst in Rudna copper mine, Poland. Int J Rock Mech Min Sci 57:113-118

Wierzbicki M, Skoczylas N (2014) The outburst risk as a function of the methane capacity and firmness of a coal seam. Arch Min Sci 59(4):1023-1031

Wodzicki A, Piestrzyński A (1994) An ore genetic model for the Lubin-Sieroszowice mining district, Poland. Miner Depos 29(1):30-43 